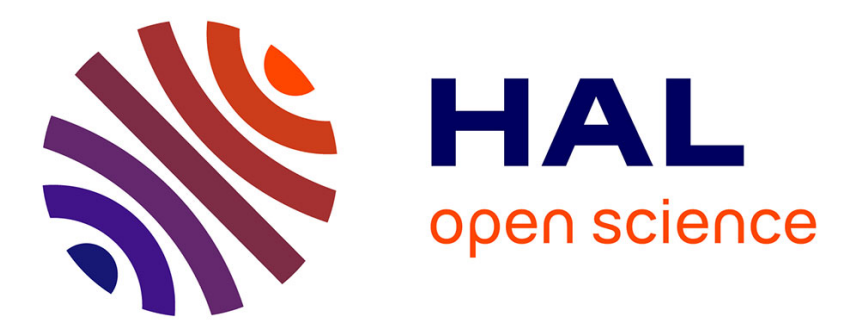

\title{
Life cycle cost analysis of ageing structural components based on non destructive condition assessment
}

\author{
Denys Breysse, Sidi Mohammed Elachachi, Emma Sheils, Franck Schoefs,
} Alan O'connor

\section{- To cite this version:}

Denys Breysse, Sidi Mohammed Elachachi, Emma Sheils, Franck Schoefs, Alan O'connor. Life cycle cost analysis of ageing structural components based on non destructive condition assessment. Australian Journal of Structural Engineering, 2009, 9 (1), pp.55-66. 10.1080/13287982.2009.11465010 . hal-01007010

\section{HAL Id: hal-01007010 https://hal.science/hal-01007010}

Submitted on 17 Jan 2017

HAL is a multi-disciplinary open access archive for the deposit and dissemination of scientific research documents, whether they are published or not. The documents may come from teaching and research institutions in France or abroad, or from public or private research centers.
L'archive ouverte pluridisciplinaire HAL, est destinée au dépôt et à la diffusion de documents scientifiques de niveau recherche, publiés ou non, émanant des établissements d'enseignement et de recherche français ou étrangers, des laboratoires publics ou privés. 


\title{
Life cycle cost analysis of ageing structural components based on non-destructive condition assessment
}

\author{
D Breysse and SM Elachachi \\ University Bordeaux 1, Ghymac, France \\ E Sheils \\ Trinity College, Dublin, Ireland \\ F Schoefs \\ GeM, Université Nantes, France \\ A O'Connor \\ Trinity College, Dublin, Ireland
}

\begin{abstract}
SUMMARY: Inspection-based maintenance strategies can provide an efficient alternative for ageing civil engineering components subjected to ageing and degradation. The technical and/or economic efficiency of such strategies depends on many factors, such as the mechanisms involved in the loss of performance; the availability, cost and efficiency of inspection techniques; the relation between what can be measured through inspections and the level of performance of the structure; the level of required serviceability of the structure; and the direct and indirect economic losses due to a reduction in the performance of a structure. On this basis, it is studied here, using Monte Carlo simulations, the benefits and limitations of an inspection-based maintenance strategy. The quality of the inspection technique is analysed in terms of its sensitivity to defects in their initial stage of development, and on its discriminant ability (detection of a real defect, while avoiding false alarms). This study is carried out with ageing characteristics, inspection models and cost assumptions that can cover a wide field of ageing assets. The influence of several factors is highlighted to see how they influence optimal strategies; a focus is given on the quality of inspections and on the allowable probability of failure.
\end{abstract}

Many of the structures that were built around the 1960s are coming to the end of their service lives and are showing significant signs of deterioration. Consequently, bridge maintenance costs are already very high and are increasing. Currently the biggest challenge that structure owners/managers face is finding the optimum balance between the increasing number of deteriorating structures, and the limited funds available for their upkeep. The demolition and replacement of large engineering structures results in high economic and environmental costs, further increasing the need for efficient management plans to maintain these structures.

As a result, a lot of research has been conducted in this area over the last decade to develop methods of maintenance management that optimise maintenance budgets (Estes \& Frangopol, 1999; Faber \& Sorensen, 2002; Kong \& Frangopol, 2003; 2004; 2005; Lauridsen et al, 2006; Radojicic et al, 2001: Stewart, 2001; 2005; Stewart et al, 2004; Stewart \& Mullard, 2006). The main objective is to find the optimal maintenance management plan, thereby optimising the lifecycle cost of the structure. Many of these methods rely on quantitative data from inspections, rather than qualitative and subjective data. Therefore, monitoring and inspections are key aspects in this process. The information from these tests can be 
used to update deterioration models and to derive the optimal economic maintenance strategy for the remaining lifetime of the structure.

The main focus of this paper is on inspection-based maintenance, and how the quality of inspection and its ability to provide useful information influence risks and costs, and change the optimal time between inspections. The maintenance strategy chosen depends on many factors, such as the rate of deterioration, the mode of failure, the correlation between the measured parameters, the performance of the structure, and the consequence of failure. The aim of this paper is to use a cost-based analysis to determine under what conditions inspection-based maintenance is an efficient strategy.

Through Monte Carlo simulations, this paper studies the benefits and limitations of inspection based maintenance strategies. The study is based upon data and models developed and used in the European Union-funded MEDACHS research project. MEDACHS is dedicated to the optimisation of the service life of structures in marine environments. Both analytical analysis and Monte Carlo simulations use deterioration models, and information supplied from inspections, to determine the most suitable inspection method along with the optimum inspection period, for different deterioration rates. The probability of detection (PoD) and probability of false alarm (PFA) are used in this study to quantify the quality of an non-destructive testing (NDT) method.

In addition, the results of this analysis are then used to compute annual total cost of a structure using inspection-based maintenance and to see, for a given set of parameters, what factors determine the optimum maintenance strategy.

\section{THEORETICAL BACKGROUND OF PROBABILISTIC MODELLING OF INSPECTION RESULTS}

The models that are used to determine the optimum maintenance management strategy arejust estimations that predict how the structure will behave over time. Since these models include uncertainty, it can be useful to carry out regular inspections to ensure that the structure is behaving as predicted, or to detect possible problems. The information from the tests can be used to update these models and come up with a more economical maintenance strategy over the remaining lifetime of the structure (Faber \& Sorensen, 2002).

Given the size of the defect, and the inspection method being used, there is a certain PoD (Faber \& Sorensen, 2002; Onoufriou \& Frangopol, 2002; Straub \& Faber, 2003). The PoD can be evaluated using:

$\operatorname{PoD}(a)=P\left(a \geq a_{d}\right)$ where $a_{d}$ is the detection threshold, under which it is assumed no crack can be detected (for a particular method), and $a$ is the measured crack length (Schoefs \& Clement, 2004). For example, Onoufriou \& Frangopol (2002) developed equation (2) to calculate the PoD that corresponds to an NDT method that has a $90 \%$ probability of detecting a $40 \mathrm{~mm}$ long crack.

$\operatorname{PoD}(2 c>x)=1-\exp (-x / 17.3)$

The PoD and PFA can be used to quantify the quality of an NDT method. A variety of NDT methods, each with different costs and quality, can be used to assess the condition of a structure over its lifetime (Onoufriou \& Frangopol, 2002). For a given crack size, ROC curves (a plot of PoD versus PFA) of different NDT methods can be used to compare the quality of different methods (Schoefs \& Clement, 2004; Rouhan \& Schoefs, 2003). For a given test, the PoD depends on the crack size, the detection threshold and noise. The PFA, however, depends only on the detection threshold and noise. Therefore, the PoD is the probability that the quantity "signal + noise" is greater than the detection threshold, and the PFA is the probability that the quantity "noise" is greater than the detection threshold (Rouhan \& Schoefs, 2003). Noise can depend on environmental conditions, human interference and the nature of what is being measured.

Rouhan \& Schoefs (2003) further developed this methodology by focusing on the probability that a defect exists after an inspection has been carried out. The PoD is the probability that an existing defect is detected, whereas a more useful parameter is the probability that a defect exists, given the results of an inspection. A decision scheme is introduced that considers four inspection events, which are represented in figure 1 and by equations (3) to (6).

$P\left(E_{1}\right)=P(X=0 \mid D(X)=0)$
$P\left(E_{2}\right)=P(X=0 \mid D(X)=1)$
$P\left(E_{3}\right)=P(X=1 \mid D(X)=0)$
$P\left(E_{4}\right)=P(X=1 \mid D(X)=1)$

where $X$ represents crack presence, and $D(X)$ represents the detection of a crack.

\section{DESCRIPTION OF DEVELOPED MODELS}

\subsection{Deterioration growth and failure models}

The simple model describing the random growth of a structural defect is:

$d(t+\Delta t) / d(t)=1+k$

where the growth rate $k$ is a Gaussian random variable, assumed to be constant for each component 


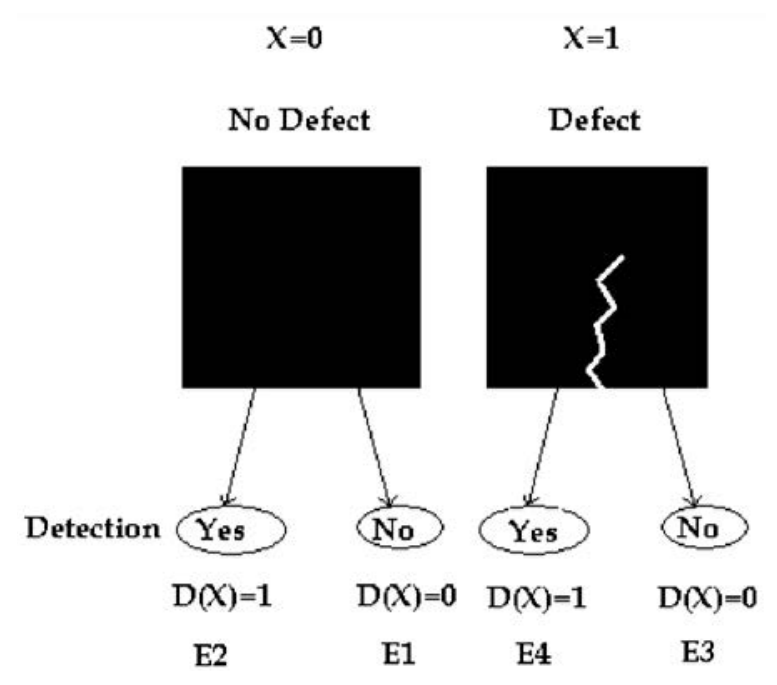

Figure 1: Four inspection events in the decision scheme.

before its failure or repair. The regular evolution of the defect size randomly varies for two consecutive cycles, from an initial defect size $d_{0}$ equal to 0.25 .

Each year, the annual probability of failure, $p_{F^{\prime}}$ is calculated using the Weibull cumulative distribution function:

$p_{F}(d)=1-\left[\exp -\left(\frac{d(t)-d_{1}}{d_{0}}\right)^{m}\right]$

where the parameter $m$ is the Weibull exponent, which determines the spread of the curve. The purpose of the limit defect size, $d_{1}$, is described by equation (9) and figure 2.

$p_{F}= \begin{cases}0 & d \leq d_{1} \\ p_{F}(d) & d>d_{1}\end{cases}$

In this context, failure must not be understood as structural failure (even if Weibull law has often been used to describe the statistical distribution of concrete or timber strength), but from a more general point of view it is the fact that a limit state is reached, as it will be discussed at section 4.3 .

\subsection{Models for decision and inspection}

The aim of optimised maintenance is to detect and repair soon enough, before the defect size reaches values for which the probability of failure (annual probability or probability between two inspections) becomes non-acceptable. The level of acceptability depends on the induced consequences of failure; since some failures have few consequences, one can accept a relatively high probability (this corresponds to the "serviceability limit states") when in other cases (eg. if lives are at stake), the acceptable level is very low. Thus the allowable annual probability of failure, $p_{F A^{\prime}}$ will be chosen after a consideration of
Pf Versus Defect Size (Weibull Curve)

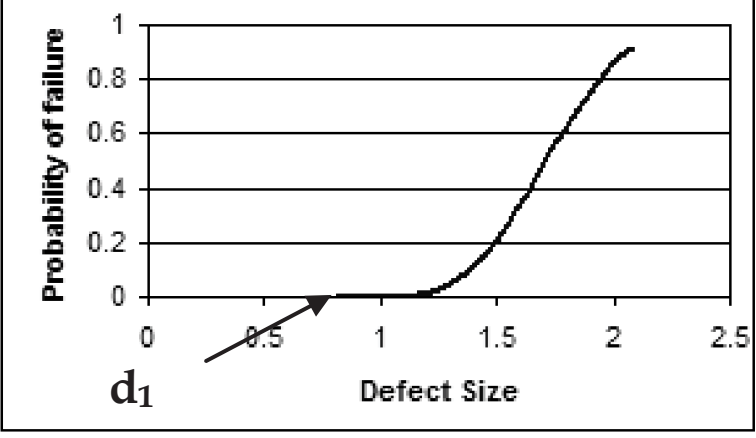

Figure 2: Effect of defect size on probability of failure

all induced costs (see section 3.3). It is thus possible to deduce the critical defect size $d_{c^{\prime}}$ corresponding to this probability, using equation (10), obtained directly from equation (8):

$d_{c}=d_{1}+d_{0}\left[-\left(\ln \left(1-p_{F A}\right)\right)\right]^{1 / m}$

Scheduled inspections are simulated every $T_{i}$ years, with a technique of known quality $Q^{\prime}$. The measurement induces a random noise, which is assumed to be a random error on the estimate of the $d$ value, following a Gaussian distribution, whose standard deviation is inversely proportional with $Q^{\prime}$. It comes the measured value $d_{\text {meas }}$.

$d_{\text {meas }}=d+n$

where $d$ is the true value and $\mathrm{n}$ the measurement noise. Depending on the respective values of $d, d_{\text {mens }}$ and $d_{c^{\prime}}$ one follows the event tree scheme where the question "exists" is replaced "with larger than critical". It is also assumed that it exist a minimum defect size $d_{\min }$ that can be detected with a technique of quality $Q^{\prime} ; d_{\min }$ increasing if $Q^{\prime}$ increases.

Figure 3 shows what is the time evolution of the defect size, combining effects of deterioration, inspection and repair. Squares correspond to the measured values assessed during inspection (here every five years). The non-perfect quality of the technique implies that the assessed values differ from the true ones. As soon as the assessed value is larger than the critical value $d_{c}$ (here taken at 0.41 ), the component is repaired and assumed to return to its initial minimal defect size $d_{0}$. A new cycle, with its own growth rate $k$, begins.

When the quality of the technique is good (thus the technique is expensive), the assessed value is near the true one. In this case, the decision for repair is generally a good decision (events E1 or E4 on figure 1). With a poor quality technique, the measurement noise is large and the assessed value can differ significantly from the true one. This often results in a premature decision for repair, since the assessed 

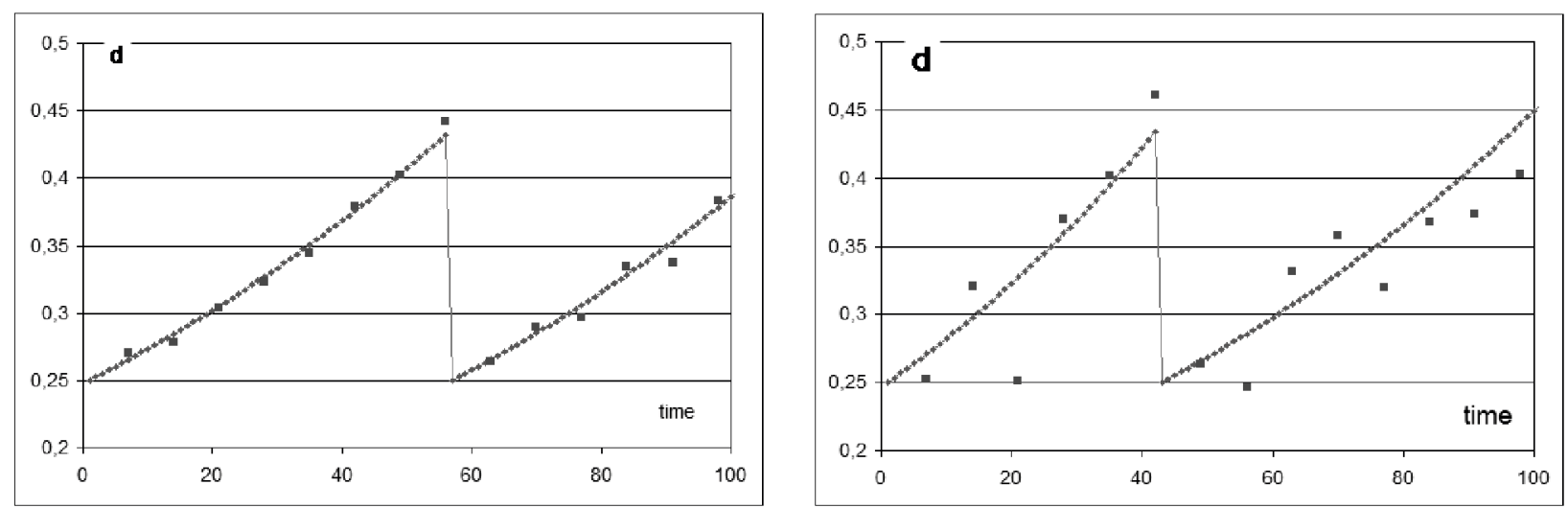

Figure 3: $\quad$ Life cycle of a component - comparison between a good $(Q=100$; left $)$ and bad technique $(Q=20$; right $)$.

value is larger than the threshold when the true one is not (event E2 on figure 1). In some cases, a defect whose size exceeds the threshold size may be missed, implying a non-detection (event E3 on figure 1).

\subsection{Expected costs}

When a scheduled inspection is carried out, every $\Delta T$ years, there are various costs involved. As well as the cost of inspection, there may also be an associated repair cost, or failure cost, both of which depend on the results from the inspection. For each inspection, there can be five possible outcomes (events $E\left(C_{01}\right)$, $E\left(C_{023}\right), E\left(C_{045}\right)$, and two variants of the latter two), with varying associated costs (see figure 4 ).

The mean annual total cost of the structure is used to determine the optimum maintenance management plan. The total cost is the sum over the period of study (or its annual average) of the building cost, inspection cost, repair cost and failure cost. The three latter costs are expressed in terms of their relative ratio to the building $\operatorname{cost} C_{0}$. Figure 4 reproduces the event tree for costs after inspection (when there is a year without inspection, the only possible costly event is failure).

\subsubsection{Inspection cost}

The cost of a single inspection is computed using:

$C_{i}=C_{0} k_{i}\left(Q^{\prime} / Q_{r e f}^{\prime}\right)^{a}$

where $C_{0}$ is the initial construction cost, $Q^{\prime}$ is the technique quality coefficient, $k_{i}$ is the inspection coefficient, and $a$ is a weighting exponent that links the quality and the cost.

\subsubsection{Repair cost}

The cost of repair is calculated using:

$C_{r}=C_{0} k_{r} d$

where $k_{r}$ is the repair coefficient and where it is assumed that the cost increases with the defect size.

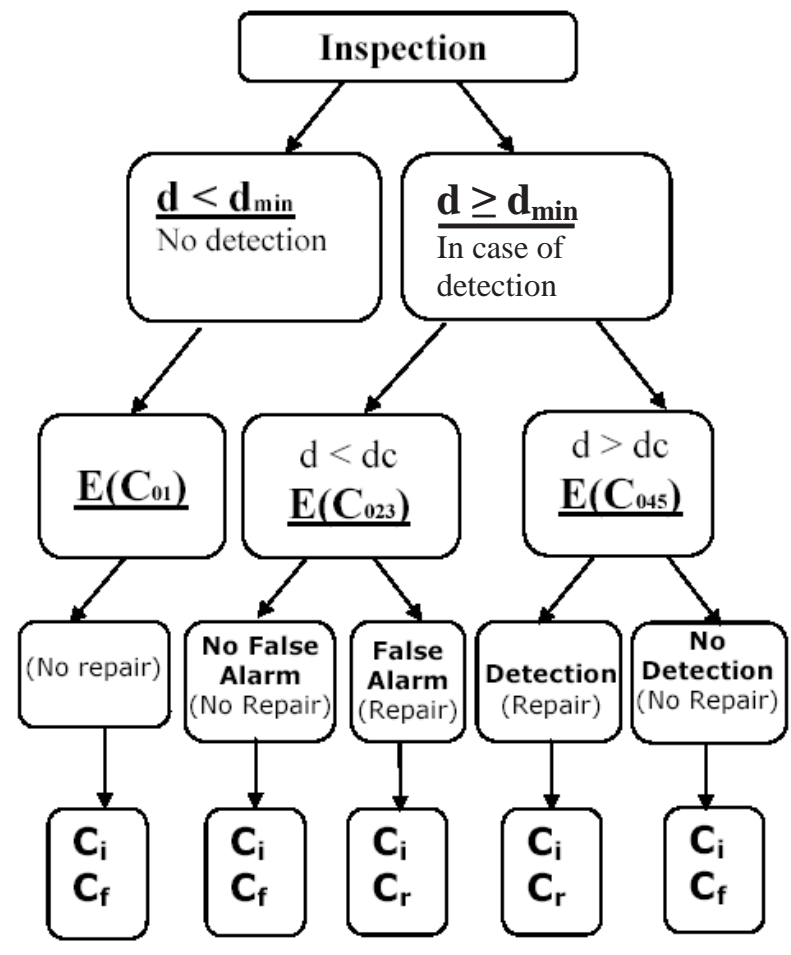

Figure 4: Event tree for outcome of inspections.

When a repair has been carried out, the size of the defect is assumed to be returned to the original size, $d_{0}$. Repair may occur due to the detection of a defect (good decision; GD), or due to a false alarm (FA). In the computations, the cost of repair is calculated separately for these two instances, so that the relative costs can be compared and the consequences of false alarms can be analysed.

\subsubsection{Failure cost}

The cost of failure of the system is also calculated relatively to the cost of construction:

$C_{f}=C_{0} k_{f}$

where $k_{f}$ is the failure impact coefficient.

For the consistency of simulations, one can wait for some link between the impact of failure and the 
annual probability of failure $p_{F A}$ defined above, which, knowing the delay $\Delta T$ between two inspections, will induce the value of the critical defect size. The reason is that when failure has important consequences, one needs to be more severe and to repair before the $p_{f}(d)$ is too large. This question will be addressed below. A discounting factor $r$ can also be introduced to account for the advantage one can have in delaying his expenses.

\section{ANALYSIS OF OPTIMAL INSPECTION STRATEGIES}

As all models are defined, it is thus possible to perform simulations. Since it has been chosen to model both the material deterioration process, the material random failure, the detection process and the associated costs, many parametric studies can be performed. It is thus necessary to focus on some specific points, such as to highlight some interesting effects.

\subsection{Optimum delay between two inspections}

In a first series of simulations, we will address the optimality of delay between inspections, the defect growth law being given, and the quality of the technique being given. We will show how the optimal solution depends on assumptions on induced costs (here through $k_{i^{\prime}} k_{r}$ and $k_{f}$ coefficients values).

Table 1 summarises the data set used for these simulations. These values lead to an average service life before failure of about 60 years without maintenance. A period of 10,000 years (about 150 to 250 service lives) was simulated. This comes to consider a component condition along 150 to 250 life cycles or to consider the average responses of 150 to 200 components during their service life.

Figure 6 synthesises results when the delay $\Delta T$ between inspections is varied between 1 and 10 years. Some comments arise:

- The number of failures increases with the delay, since the failure probability increases and two inspections with a too large delay cannot prevent it (the defect is below the critical threshold at the first inspection).

- The number of repairs after a false alarm is larger than that of repair undertaken on the basis of a good decision, and this difference is larger when the delay decreases. This comes from the error measurements, whose consequence is (with a $50 \%$ probability) the overestimation of the defect size, which leads to many repairs before needed (see figure 4). A direct consequence is that the average service life jumps from less than 40 years (38.1 $=10000 / 262.6$ if $\Delta T=1$ year) to more than 50 years $(53.0=10000 / 188.6$ if $\Delta T=10$ years $)$.
Table 1: Characteristics assumed in the four models.

\begin{tabular}{|c|c|}
\hline Model properties & \\
\hline \multicolumn{2}{|l|}{ Growth of defect } \\
\hline $\begin{array}{l}\text { Growth rate (mean } \mu_{k^{\prime}} \text { standard } \\
\text { deviation } \sigma_{k} \text { ) }\end{array}$ & $0.01,0.002$ \\
\hline Initial defect size, $d_{0}$ & 0.25 \\
\hline \multicolumn{2}{|l|}{ Probability of failure } \\
\hline Probability of failure exponent, $m$ & 4 \\
\hline Limit defect size, $d_{1}$ & 0.33 \\
\hline $\begin{array}{l}\text { Allowable annual probability of } \\
\text { failure, } p_{F A}\end{array}$ & 0.01 \\
\hline \multicolumn{2}{|l|}{ NDT } \\
\hline Detection threshold, $d_{\min }$ & 0.3425 \\
\hline Quality of inspection, $Q^{\prime}$ & 8 \\
\hline Reference quality, $Q_{r e f}^{\prime}$ & 20 \\
\hline Cost exponent & 0.5 \\
\hline \multicolumn{2}{|l|}{ Cost analysis } \\
\hline Initial construction cost, $C_{0}$ & 1000 \\
\hline Inspection coefficient, $k_{i}$ & 0.005 \\
\hline Repair coefficient, $k_{r}$ & 0.05 \\
\hline Failure impact coefficient, $k_{f}$ & 1 \\
\hline Discounting factor, $r$ & 0 \\
\hline
\end{tabular}

Costs calculated for varying $\Delta T$ delay are compared on figure 6. Inspection costs, repair costs (distinguishing those due to false alarm and those due to good decision) and failure induced costs are considered separately. With the chosen set of parameters, the repair cost remains small and the optimum delay value is determined by the fact that, if the delay increases, the inspection costs decrease and the failure costs increase. The resulting optimum is here equal to four years.

Figure 7 gives the results for the same simulations for a variant in which only cost weights have been changed (table 2). In this case, one has given a larger weight to repair costs. The result is an increase of the optimum interval, with a best result for six or seven years. The shape of the function shows that it is very sensitive to economical assumptions.

\subsection{Effect of the inspection quality}

The inspection quality $Q^{\prime}$ has an influence on the ability of detecting sooner (via the $d_{\min }$ value), of taking good decisions (because a higher quality reduces the noise measurement $n$, equation (11)) and on inspection cost (equation (12)). Figure 8 shows 


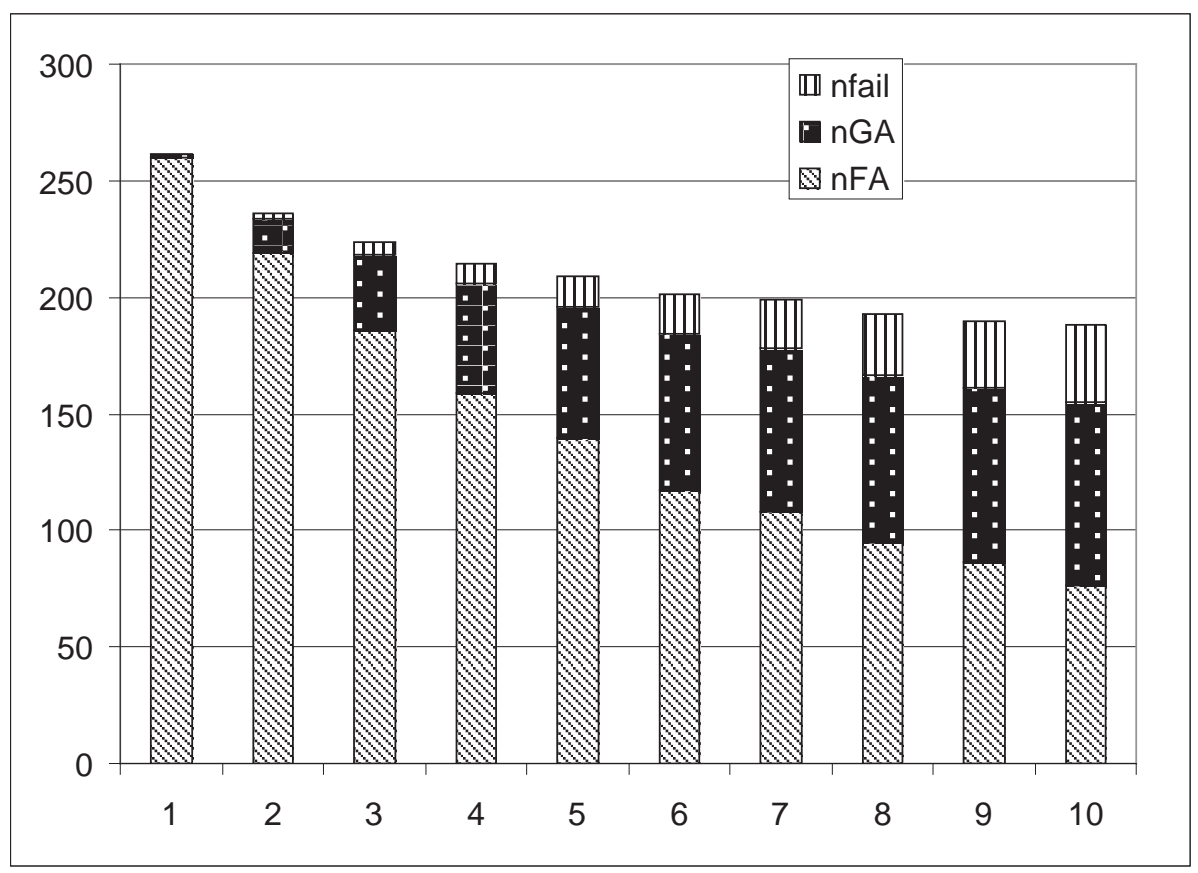

Figure 5: Number of possible causes of end of life, as a function of delay $\Delta T$ between two inspections.

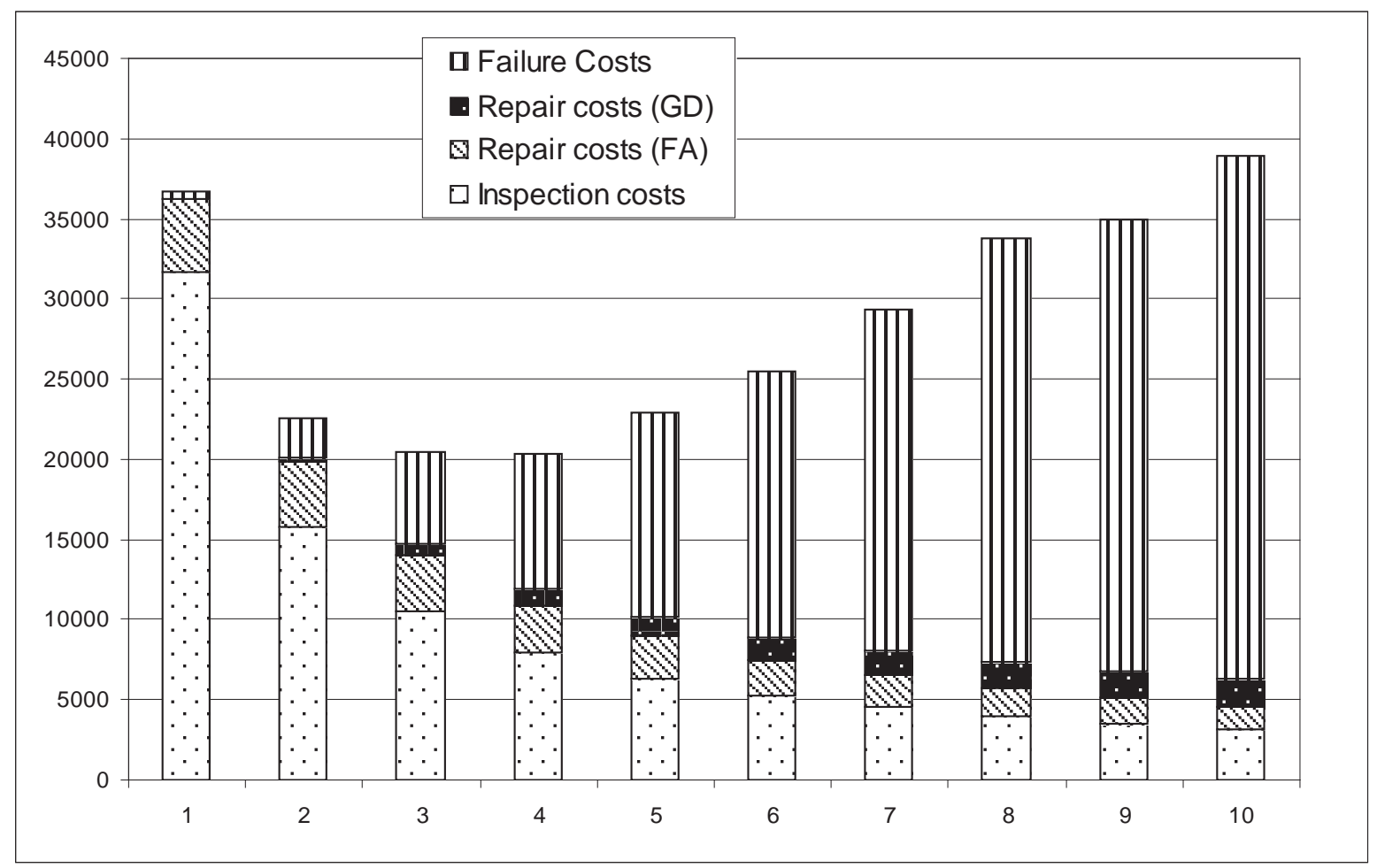

Figure 6: Variation of average costs as a function of delay $\Delta T$ between inspections.

what is the influence of the quality of the technique, when it is varied from $Q^{\prime}=5$ to $Q^{\prime}=512$. Unit cost data are those of Case $C$ (table 2) and a constant delay $\Delta T=7$ years is assumed between inspections.

The simulation shows that the optimum is obtained for a technique of an average quality. A too sophisticated technique is too expensive without decreasing significantly the repair and failure costs (for this $\Delta T$ value and this defect growth kinetics), while a too rough technique, even cheap, leads to too many repairs and thus increases the corresponding costs.

\subsection{Effect of the allowable probability of failure}

In the previous simulations, the allowable annual probability of failure was fixed $\left(p_{F A}=10^{-2}\right)$. If one considers that this parameter is itself a degree of freedom during the design process, this enriches the optimisation process, since the "optimal solution" (in terms of minimum cost) will correspond to an optimal set of $\Delta T, Q^{\prime}$ and $p_{F A}$. The allowable annual probability of failure $p_{F A}$ is varied in the following from 


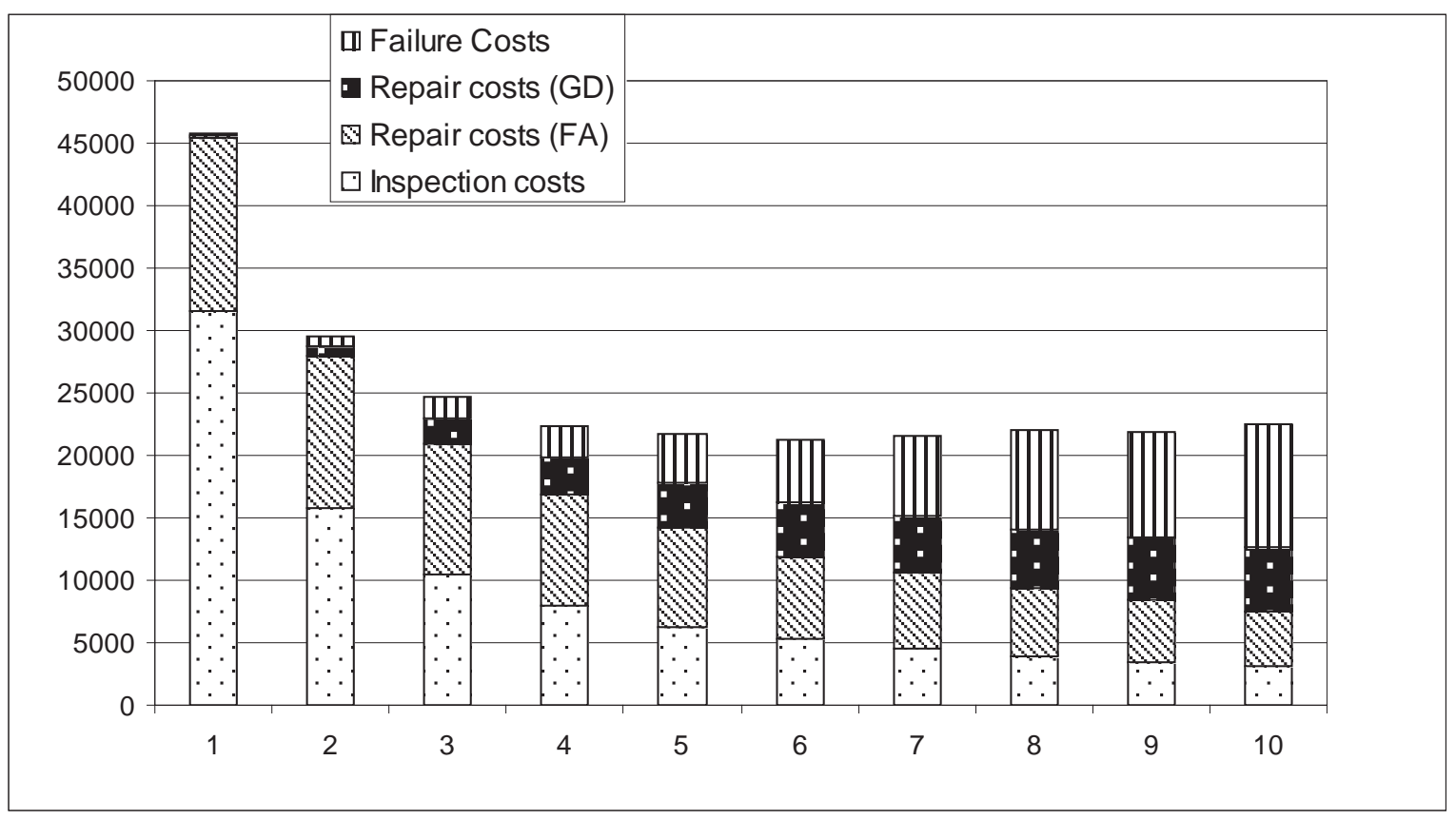

Figure 7: $\quad$ Variation of average costs as a function of delay $\Delta T$ between inspections (Case B).

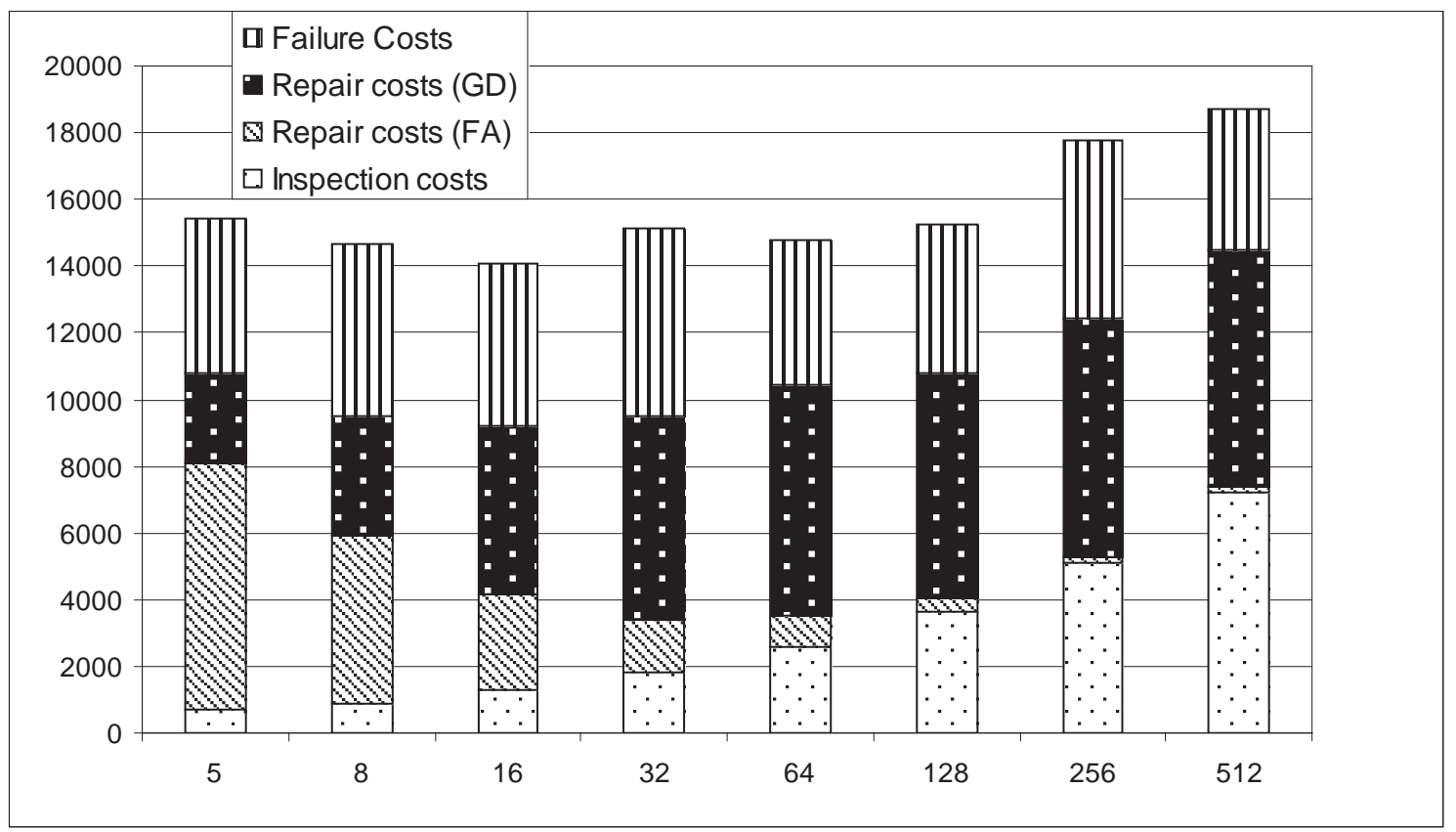

Figure 8: Influence of the quality of the technique on costs (simulation, Case C).

Table 2: $\quad$ Unit costs for three variants of simulation.

\begin{tabular}{|c|c|c|c|}
\hline & Reference simulation (Case A) & Variant (Case B) & Variant (Case C) \\
\hline Inspection $k_{i}$ & 0.005 & 0.005 & 0.001 \\
\hline Repair $k_{r}$ & 0.05 & 0.15 & 0.15 \\
\hline Failure $k_{f}$ & 1 & 0.3 & 0.3 \\
\hline
\end{tabular}

$10^{-4}$ to $10^{-1}$. This range of values mainly corresponds to a Serviceability Limit State, since it gives $0.5 \%$ probability to near certainty for a 50 -year period.

A second series of simulations has been undertaken such as to better understand this point. The number of simulations corresponds to about 2500 to 4500 life cycles, depending on the data set. This number being larger than in the first series (section 4.1), it improves the quality of convergence and reduces the computational noise that could be seen on figures 6 to 8 . Figures 9 to 11 show how, as a function of $\Delta T$ 

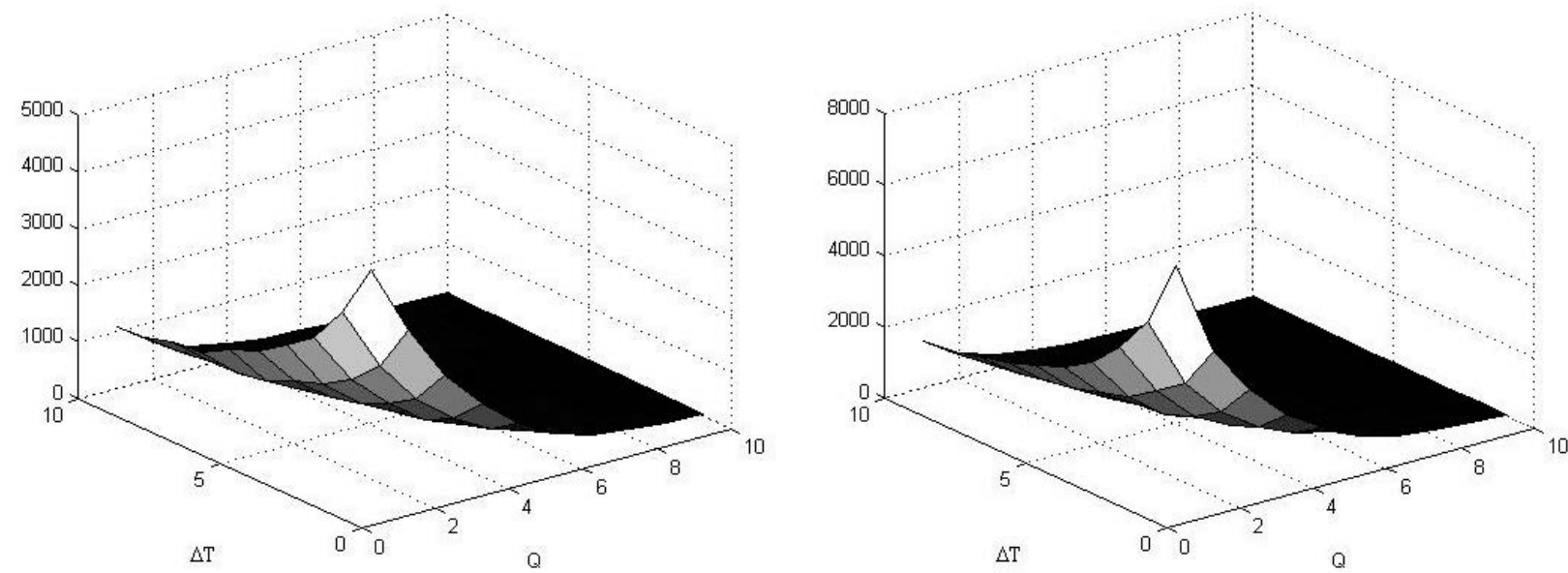

Figure 9: Number of false alarms as a function of technique quality $Q$ and delay between inspections $\Delta T$ (left: $p_{F A}=10^{-2}$; right: $p_{F A}=10^{-3}$ ).
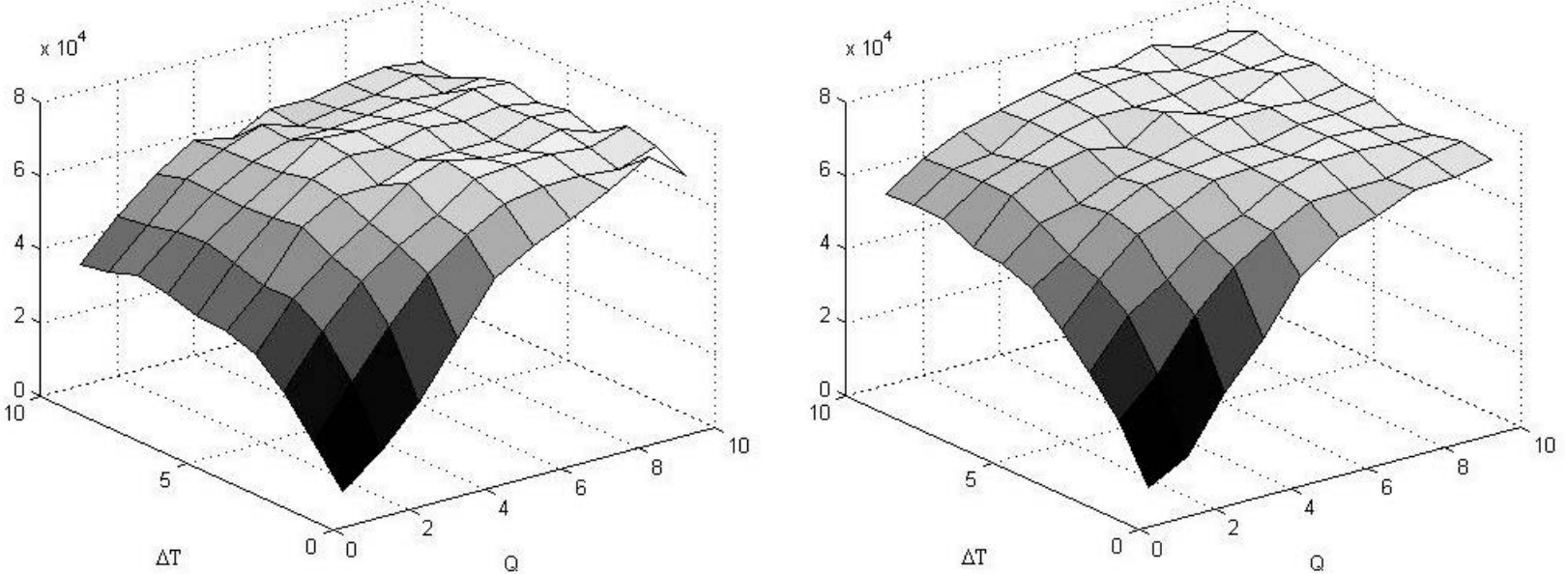

Figure 10: Number of good detections as a function of technique quality $Q$ and delay between inspections $\Delta T$ (left: $p_{F A}=10^{-2}$; right: $p_{F A}=10^{-3}$ ).
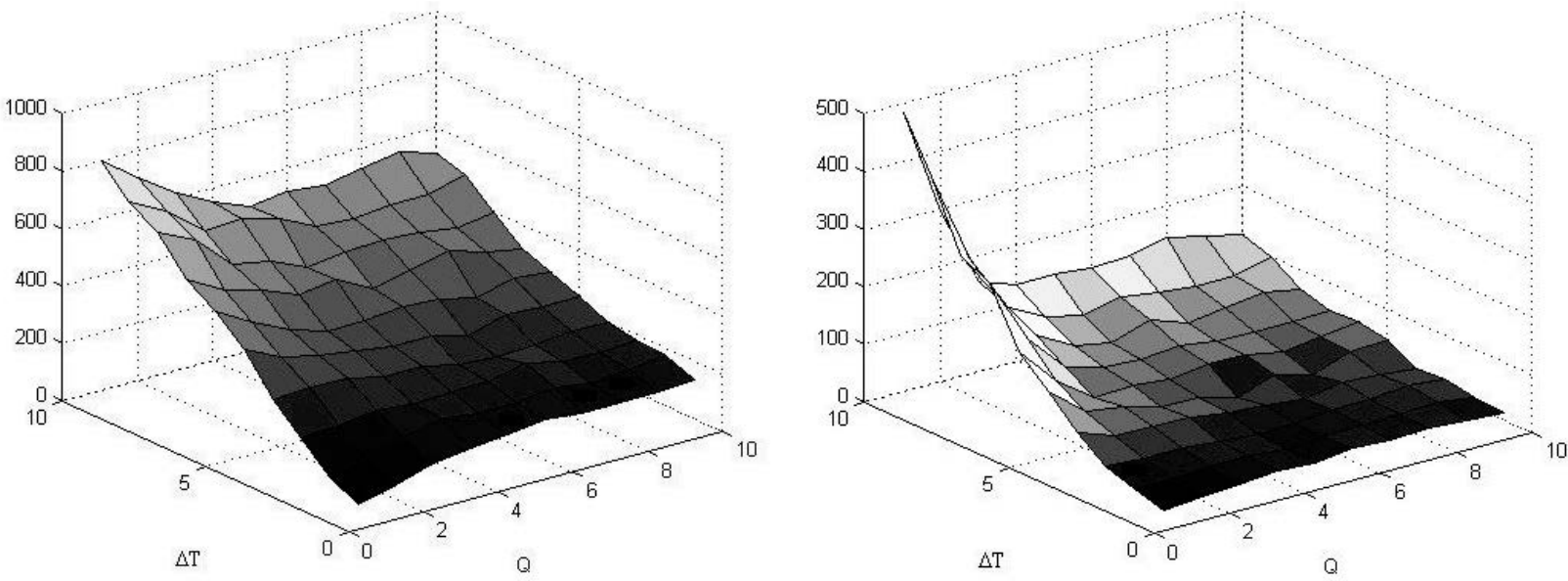

Figure 11: Number of failures as a function of technique quality $Q$ and delay between inspections $\Delta T$ (left: $p_{F A}=10^{-2}$; right: $p_{F A}=10^{-3}$ ).

and $Q$ the number of false alarms (nFA), the number of good decisions (nGA) and the number of failures (nfail) are respectively varying, for two $p_{F A}$ values. The quality $Q^{\prime}$ has been replaced by $Q$, with:

$Q^{\prime}=2^{Q}$ such as to see better the influence of the technique quality. Thus the value $Q^{\prime}=8$ used above corresponds to $Q=3$. The same patterns can be seen for the two probability values and the shape of the surfaces is compatible with what has been observed previously on figure 5. For instance, the number of false alarms decreases (since the techniques induces some noise) 
when the $\Delta T$ delay increases. However, for a good or very good technique $\left(Q>5\right.$ or $\left.Q^{\prime}>32\right)$, the number of false alarms is very low. Figure 11 shows that the total number of failures normally increases when $\Delta T$ delay increases, but it increases less when a good technique is used.

It can also be seen that changing the $p_{F A}$ value has two adverse consequences in terms of total cost: a more severe probability of failure decreases the number of failures when it increases the number of repairs (the average service life is reduced since the threshold value of the defect size for repair is lowered). This proves that this value of the allowable probability is of worth to be considered for optimisation.

Since all results regarding optimal costs also depend on what is assumed on single costs $\left(k_{i} k_{r}\right.$ and $k_{f}$ coefficients introduced in equations (12) to (14)), it has been decided to choose some sets of values for these coefficients and to look at optimality for the $\left\{\Delta T, Q, p_{E A}\right\}$ set. For practical applications, it will of course be necessary to identify, from field data, the real relative ratio between inspection, repair and failure cost corresponding to any real asset management project.

Figure 12 shows what has been obtained with two slightly different sets:

- Set A: $k_{i}=0.0007, k_{r}=0.1, a=0.06, k_{f}=1$

- Set B: $k_{i}=0.0007, k_{r}=0.1, a=1.5, k_{f}=1$.

The main difference between the two sets is the $a$ coefficient (cost exponent defined in equation (12)), which quantifies how the inspection cost increases with the quality of the technique. A high value of this coefficient (Set B) penalises very good techniques whose technical efficiency for detection of critical defects is not counterbalanced against their cost. The surfaces have been built by considering four values of $p_{F A}=\left\{10^{-1}, 10^{-2}, 10^{-3}, 10^{-4}\right\}$ and by keeping that corresponding, for each $\{\Delta T, Q\}$ set, to the lower cost.

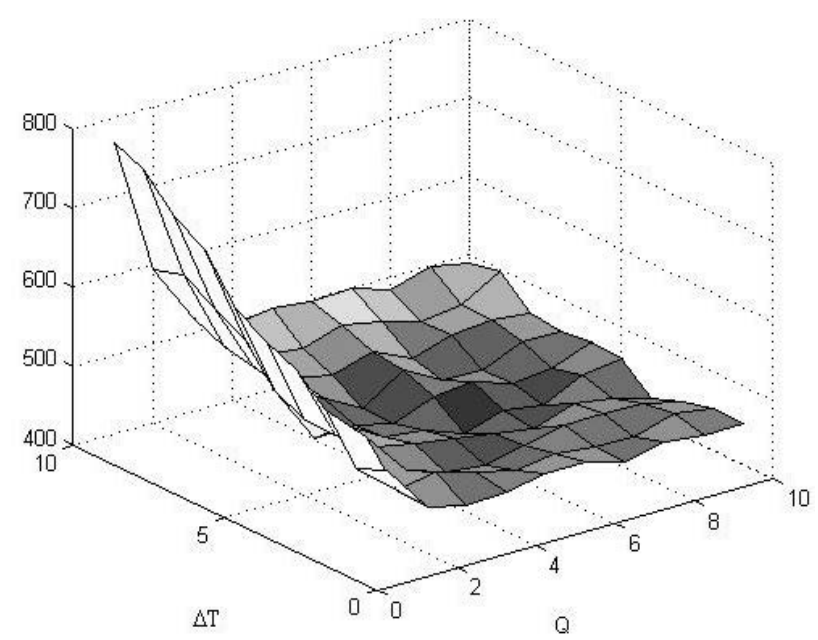

The optimal solution, respectively, corresponds to the range $\left\{p_{F A^{\prime}} \Delta T, Q\right\}=\left\{10^{-3}, 5,6-7\right\}$ with the Set $A$ and to $\left\{p_{F A^{\prime}}, \Delta T, Q\right\}=\left\{10^{-3}, 6,3-4\right\}$ with the Set $\mathrm{B}$, confirming the high sensitivity of the optimal strategy to the input values. In fact, this shows that, if the cost of inspections quickly increases with their quality (Set B), it is better to use a rough technique and to have a large delay between inspections, which can cause a significant number of failures. On the contrary, if the quality of the inspection does not imply a high additional cost, this justifies to use more frequently a more accurate technique, thus reducing the number of failures (Set A). The observed number of failures decreases from about 50 (Set B) to less than 20 (Set A) for 100,000 years of simulation, which comes to an annual probability of failure of about $0.510^{-3}$ (Set B) to $0.210^{-3}$ (Set A). These values are well below the $p_{F A^{\prime}}$ values since they include the effects of preventive maintenance (when the defects would lead to a larger probability of failure, inspection and maintenance tend to renew the component).

\section{CONCLUSIONS}

This study demonstrates that the cost and the quality of inspections have a significant influence on the optimum delay between inspections, and hence the minimum annual total cost of the structure over its lifetime.

In general, inspection-based maintenance provides a more economical alternative to systematic maintenance, as repairs are only carried out based on the results obtained from inspections. Also, the extent of a repair is based on the size of the defect that was detected by the inspection. However, it has to be accounted for that the inspection-based maintenance requires that the repair decision is taken on firm basis, assuming correct information provided by accurate techniques. If it is not the case, over-cost can be induced by too conservative decisions.

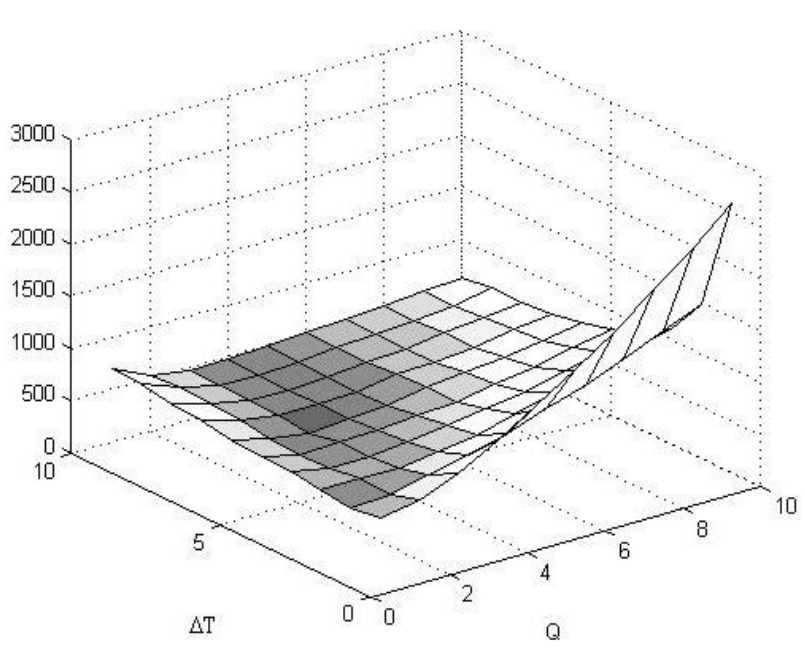

Figure 12: Total cost as a function of quality $Q$ of the technique and delay $\Delta T$ between inspections (left: Set A; right: Set B). 
Of course, since many parameters describe the whole system (defect growth, detection process, manager's choices, economics), it is not possible to draw universal conclusions. It is possible to study the influence of few parameters while considering the others as constant, but many coupling effects exist and the quantitative results (regarding optimality) depend on these assumptions. It is the reason why it can be interesting to devote more specific studies to the relations between inspection quality and inspection cost. The simulation, however, offers, in its present state, a very powerful tool for a better understanding of the role of each parameter in a such complex context.

Therefore, to build the optimum maintenance management plan, it is necessary to have accurate models for deterioration, inspections and repair, and to have a good understanding of the influencing parameters involved in each of these stages. Further work is being carried out as part of the French SENSO project to investigate the quality of information provided by a variety of NDT techniques on several parameters quantifying the condition of concrete.

\section{REFERENCES}

Estes, A. C. \& Frangopol, D. M. 1999, “Repair optimization of highway bridges using system reliability approach", Journal of Structural Engineering, ASCE, Vol. 125, No. 7, pp. 766-775.

Faber, M. H. 2002, “RBI: An Introduction”, Structural Engineering International, Vol. 3, pp. 187-194.

Faber, M. H. \& Sorensen, J. D. 2002, “Indicators for inspection and maintenance planning of concrete structures", Journal of Structural Safety, Vol. 24, pp. 377-396.

Kong, J. S. \& Frangopol, D. M. 2003, “Life-cycle reliability-based maintenance cost optimization of deteriorating structures with emphasis on bridges", Journal of Structural Engineering, ASCE, Vol. 129, No. 6, pp. 818-828.

Kong, J. S. \& Frangopol, D. M. 2004, “Costreliability interaction in life-cycle cost optimization of deteriorating structures", Journal of Structural Engineering, ASCE, Vol. 130, No. 11, pp. 1704-1712.

Kong, J. S. \& Frangopol, D. M. 2005, “Probabilistic optimization of ageing structures considering maintenance and failure costs", Journal of Structural Engineering, ASCE, Vol. 131, No. 4, pp. 600-616.

Lauridsen, J., Bjerrum, J., Sloth, M. \& Jensen, F. M. 2006, "Principles for a guideline for probability-based management of deteriorated bridges", IABMAS 2006 Conference, Bridge Maintenance, Safety and Management, Porto.

Onoufriou, T. \& Frangopol D. M. 2002, "Reliabilitybased inspection optimisation of complex structures: a brief retrospective", Journal of Computers and Structures, Vol. 80, No. 12, pp. 1133-1144.

Radojicic, A., Bailey, S. F. \& Brühwiler, E. 2001, "Probabilistic models of cost for the management of existing structures", Life-Cycle Cost Analysis and Design of Civil Infrastructure Systems, SEI-ASCE, August.

Rouhan, A. \& Schoefs, F. 2003, "Probabilistic modeling of inspection results for offshore structures", Journal of Structural Safety, Vol. 25, No. 4, pp. 379-399.

Schoefs, F. \& Clement, A. 2004, "Multiple inspection modeling for decision making and management of jacket offshore platforms: effect of false alarms", International Forum on Engineering Decision Making, Stoos, Switzerland.

Stewart, M. G. 2001, "Reliability based assessment of ageing bridges using risk ranking and life cycle cost decision analyses", Reliability Engineering and System Safety, Vol. 74, pp. 263-273.

Stewart, M. G. 2005, "Life-cycle cost analysis considering spatial and temporal variability of corrosion-induced damage and repair of concrete surfaces", ICOSSAR 2005.

Stewart, M. G. \& Mullard, J. A. 2006, “Reliability based assessment of the influence of concrete durability on the timing of repair for RC bridges", IABMAS 2006 Conference, Bridge Maintenance, Safety and Management, Porto.

Stewart, M. G., Estes, A. C. \& Frangopol, D. M. 2004, "Bridge deck replacement for minimum expected cost under multiple reliability constraints", Journal of Structural Engineering, ASCE, Vol. 130. No. 9, pp. 1414-1419.

Straub, D. \& Faber, M. H. 2003, "Modeling dependency in inspection performance", Applications of Statistics and Probability in Civil Engineering, Rotterdam. 